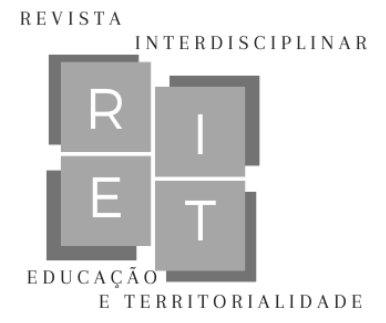

\title{
Impacto do ensino remoto na formação dos discentes do curso de Engenharia Agronômica: UEMG Unidade Ituiutaba - MG
}

\author{
The impact of remote education on the training of students of the Agronomic \\ Engineering course - UEMG Unidade Ituiutaba - MG
}

Impacto de la educación remota en la formación de estudiantes de Ingeniería Agrícola - UEMG Unidade Ituiutaba - MG

\author{
Mônica Miguel de Paula \\ Universidade do Estado de Minas Gerais, Unidade de Ituiutaba (UEMG) \\ Ituiutaba, Minas Gerais, Brasil \\ E-mail: monicampaula@ hotmail.com \\ ORCID: 0000-0002-4249-2416
}

\begin{abstract}
Ana Cecília Guedes
Universidade do Estado de Minas Gerais, Unidade Ituiutaba (UEMG) Ituiutaba, Minas Gerais, Brasil E-mail: ana.cecilia@uemg.br ORCID: 0000-0001-8814-4858
\end{abstract}

Elicardo Heber de Almeida Batista Universidade do Estado de Minas Gerais, Unidade Ituiutaba (UEMG) Ituiutaba, Minas Gerais, Brasil E-mail:elicardo.batista@uemg.br ORCID: 0000-0002-3961-3088

Resumo: Na atualidade é inevitável não considerar a pandemia causada pelo vírus COVID19 e seus impactos na vida, na sociedade, nas mais distintas atividades econômicas, e na educação. O objetivo principal da investigação foi identificar e analisar o impacto do ensino remoto na formação dos discentes do curso de Engenharia Agronômica oriundos da Universidade do Estado de Minas Gerais - Unidade Ituiutaba. Trata-se de uma pesquisa quali-quantitativa. A coleta de dados foi composta pela aplicação de um questionário online com questões abertas e fechadas para os estudantes do referido curso, o índice de resposta foi representado por um total de 158 discentes. Os resultados apontam que atual modalidade de ensino não é o mais favorável, pois a maior parte dos discentes vem enfrentando dificuldades, principalmente no que concerne à parte prática do curso. Porém conclui-se que ainda é a forma mais indicada devido o cenário atual.

Palavras-chave: Eduçação. Pandemia. Agronomia.

Abstract: Nowadays, it is inevitable not to consider the pandemic caused by the COVID-19 virus and its impacts on life, society, the most different economic activities, and education. The main objective of the investigation was to identify and analyze the impact of remote education on the training of students in the Agronomic Engineering course from the State 


\section{Impacto do ensino remoto na formação dos discentes do curso de engenharia agronômica: UEMG Unidade Ituiutaba - MG}

University of Minas Gerais - Ituiutaba Unit. It is a qualitative and quantitative research. The data collection was composed by the application of a questionnaire with open and closed questions for the students of that course, the response rate was represented by a total of 158 students. The results show that the current teaching modality is not the most favorable, as most students have been facing difficulties, especially with regard to the practical part of the course. However, it is concluded that it is still the most suitable form due to the current scenario.

Keywords: Education. Pandemic. Agronomy.

Resumen: Hoy en día es inevitable no considerar la pandemia provocada por el virus COVID-19 y sus impactos en la vida, en la sociedad, en las más diversas actividades económicas y en la educación. El objetivo principal de la investigación fue identificar y analizar el impacto de la educación a distancia en la formación de estudiantes de la carrera de Ingeniería Agronómica de la Universidad Estatal de Minas Gerais - Unidad Ituiutaba. Es una investigación cualitativa y cuantitativa. La recolección de datos estuvo compuesta por la aplicación de un cuestionario con preguntas abiertas y cerradas para los estudiantes de ese curso, la tasa de respuesta estuvo representada por un total de 158 estudiantes. Los resultados muestran que la modalidad docente actual no es la más favorable, ya que la mayoría de los estudiantes han ido enfrentando dificultades, especialmente en lo que respecta a la parte práctica del curso. Sin embargo, se concluye que sigue siendo la forma más adecuada debido al escenario actual.

Palabras llave: Educación. Pandemia. Agronomía.

Data de recebimento: $29 / 03 / 2021$

Data de aprovação: 10/06/2021

DOI: $10.30612 /$ riet.v\%vi\%i.14468

\section{Introdução}

No vigente cenário é inevitável não se considerar a pandemia causada pelo vírus COVID-19 e seus impactos na vida, na sociedade, nas mais distintas atividades econômicas, e na educação. Desde dezembro de 2019, quando foram apresentados os primeiros casos em parte do território chinês, as infecções por corona vírus têm se alastrado principalmente em países como, Estados Unidos, Reino Unido, Itália, Espanha, França e Brasil.

Entretanto, com a "compressão espaço-tempo" (HARVEY, 1999) e uma sociedade cada vez mais organizada em distintas redes e conectada das mais diversas formas (CASTELLS, 1999), o vírus espalhou-se globalmente desconsiderando fronteiras políticas ou a diversidade dos povos. Esse vírus é um problema global, tanto que em março de 2020, foi reconhecido pela Organização Mundial da Saúde (OMS) como um fenômeno catastrófico de enfermidade epidêmica amplamente disseminada, denominado como pandemia ${ }^{1}$.

\footnotetext{
${ }^{1}$ Pandemia, palavra de origem grega, formada com o prefixo neutro pan e demos, povo, foi pela primeira vez empregada por Platão, o qual a utilizou num sentido genérico, referindo-se a qualquer acontecimento capaz de alcançar toda a população. No mesmo sentido foi também utilizada por Aristóteles. Já Galeno utilizou o
} 


\section{Impacto do ensino remoto na formação dos discentes do curso de engenharia agronômica: UEMG Unidade Ituiutaba - MG}

Nesse sentido, têm-se uma maior necessidade de estudos que apontem a cura, ou vacinas que busquem controlar a disseminação dessa doença, porém até o presente momento o sucesso é algo distante, tendo como melhor eficácia, o distanciamento social e medidas sanitárias $^{2}$ impostas pela Organização Mundial da Saúde (OMS). Nesse processo de distanciamento social, locais que possuíam aglomerações foram classificados como vetores de rápida propagação, sendo obrigados a suspender suas atividades. Dentre estes locais, pode-se citar os estádios de futebol, as casas de festas, as escolas, faculdades e universidades. Passando a funcionar somente o que é considerado serviço essencial tais como: assistência à saúde, assistência social e atendimento à população em estado de vulnerabilidade, atividades de segurança pública e privada, entre outros.

Mediante esta suspensão de atividades dos serviços não considerados essenciais, e sem a previsão de retorno, discussões começaram a surgir na perspectiva de elaboração de estratégias para atender as demandas da população. No setor educacional não foi diferente; escolas, faculdades e universidades precisaram começar a pensar estratégias de como dar continuidade ao semestre letivo, e por quais meios continuariam a levar o ensino às crianças, jovens e adultos.

A Universidade do Estado de Minas Gerias (UEMG), inicialmente criou uma Comissão Especial de Enfrentamento e Monitoramento da COVID-19 a qual vem elaborando informes com o intuito de acompanhar, divulgar e subsidiar o enfrentamento da COVID-19. O curso de Engenharia Agronômica desta universidade, no final de maio do presente ano, criou o projeto "Semeando Saberes - Engenharia Agronômica/ UEMG", com o objetivo de oferecer cursos, palestras e rodas de conversa para estudantes de graduação, egressos e comunidade interessada, como uma forma de manter o vínculo entre universidade, professores, estudantes e comunidade, favorecendo o processo ensino-aprendizagem. Por fim, em meados de junho de 2020 a universidade aplicou um questionário aos docentes e discentes sobre o retorno das aulas, sobre a realização de atividades remotas.

Iniciou-se um processo de discussão e preparação de forma a retornar suas atividades por meio do ensino remoto, já que não seria possível o retorno das atividades presenciais.

adjetivo pandémico em relação a doenças epidêmicas de grande difusão. O conceito moderno de pandemia é o de uma epidemia de grandes proporções, que se espalha a vários países e a mais de um continente (REZENDE, 1998, p.154)

${ }^{2}$ Essas medidas incluem a higienização das mãos com água e sabão e uso de álcool em gel. Também recomenda-se evitar tocar olhos, nariz e boca, e proteger as pessoas ao redor ao espirrar ou tossir e a utilização de máscara 


\section{Impacto do ensino remoto na formação dos discentes do curso de engenharia agronômica: UEMG Unidade Ituiutaba - MG}

Sendo assim, a mesma buscou analisar e apresentar meios para propor a seus discentes um ensino de qualidade e que abrangesse a maioria sem exclusão, visto que é uma unidade socioeducativa que acolhe estudantes de variadas classes sociais, oriundas de meio rural e urbano, que possuem inúmeras limitações e fragilidades (UEMG, 2020).

No final do mês de julho de 2020 ocorreu a retomada das atividades na modalidade Ensino Remoto. Neste contexto, o presente trabalho busca identificar e analisar, quais os pontos positivos e negativos do ensino remoto e seus impactos na formação dos discentes do Curso de Engenharia Agronômica da UEMG - Unidade Ituiutaba. Para atender ao objetivo proposto foi elaborado e encaminhando um questionário na plataforma Google Docs aos discentes do curso de Engenharia Agronômica da UEMG, tendo um percentual de retorno de $45,8 \%$ dos discentes do curso. A partir desse retorno as questões foram tabuladas e analisadas com auxílio do Excel para as questões fechadas e análise de discurso para as questões abertas.

O presente artigo está estruturado em três seções, além desta introdução e considerações finais. A primeira seção discorre sobre a revisão bibliográfica que busca descrever o processo educativo de ensino remoto. Na segunda seção é apresentada a metodologia do estudo e por fim na terceira seção são apresentados e discutidos os resultados deste estudo.

\section{Fundamentação Teórica}

\section{O COVID-19 e sua relação com a educação}

O vírus nomeado COVID-19, originou-se na China, teve seu primeiro caso relatado em dezembro de 2019, atingindo mais de 180 países, de acordo com o Jornal da Universidade de São Paulo - (USP). O primeiro artigo científico publicado sobre o tema, foi obra dos chineses, o qual descreveu o relato de um paciente de 41 anos, tal pesquisa apontou que a secreção broncoalveolar possuía uma semelhança gigantesca com o genoma do vírus da Sars e Mers, o que levou então a suposição do novo coronavírus ser suscitado pelos morcegos, assim como os outros dois vírus citados. O COVID-19 possui um grau de contaminação e disseminação muito alto, o que o leva a caracterização de uma das maiores pandemias já acontecidas na história mundial (GRUBER, 2020).

As consequências deixadas por este vírus ainda não podem ser mensuradas. Houve o fechamento de instituições de ensino, com também o fechamento de vários outros ramos, 


\section{Impacto do ensino remoto na formação dos discentes do curso de engenharia agronômica: UEMG Unidade Ituiutaba - MG}

bem como uma queda bruta da economia de todo o mundo. As relações sociais foram imensamente atingidas, pois o ser humano, que é um ser totalmente sociável se viu trancafiado em seu lar, sem contato com entes queridos, amigos, dentre outros.

Além disso, na conjuntura atual é inevitável não tocar no assunto da pandemia causada pelo vírus COVID-19 e das suas consequências. No que concerne ao setor educacional de acordo com a Organização das Nações Unidas para a Educação, a Ciência e a Cultura (Unesco), o colapso ocasionado pela COVID-19 sucedeu no cancelamento das aulas em universidades e escolas, abrangendo mais de $90 \%$ dos estudantes do mundo todo (UNESCO, 2020).

Ainda segundo a Unesco (2020), o fechamento de escolas e universidades trouxe muitas consequências negativas, que de maneira geral, podem ser caracterizadas como: a aprendizagem interrompida, pois muitos não têm oportunidades de um ensino remoto; má nutrição de alunos carentes, visto que muitos jovens dependiam do alimento oferecido em seus lugares de estudos; confusão e estresse para professores; dificuldade para mensurar e validar a aprendizagem.

As Tecnologias de Informação e Comunicação (TICs) vêm sendo usadas cada vez mais nesse contexto de pandemia. As pessoas estão tendo contato unicamente por uma tela quadrada (computadores, celulares) e aliado a isso tem-se uma problemática ainda maior, que consiste na quantidade de indivíduos que não tem acesso à tecnologia. Aos que têm essa aproximação com os meios de comunicação, a abundância de informações se faz muita das vezes maléficas para a saúde mental destes, informações falsas e alteradas sendo distribuídas sem controle algum, à nível global, causando grande impacto (LIMA, 2020, p.73).

\section{O desafio do remoto no ensino superior}

A expressão "acesso remoto" refere-se à ligação de duas palavras com significado individual. De acordo com o dicionário de língua portuguesa (BUARQUE, 1999) “Acesso” significa: abeiramento, aproximação, chegada; e "remoto" refere-se a algo distante, afastado. A partir dos significados poderia se definir, então, que acesso remoto é uma ferramenta de aproximação que se encontra muito distante ou em um lugar afastado.

O ensino remoto tem por objetivo, quebrar distância e fazer com que todos os indivíduos que usufruem desta tecnologia possam se beneficiar com informações e contatos, que este permite. No entanto, esse papel facilitador nem sempre acontece, pois existem muitas variáveis que justificam a não adequação a esse tipo de ensino, tais como: a falta de 


\section{Impacto do ensino remoto na formação dos discentes do curso de engenharia agronômica: UEMG Unidade Ituiutaba - MG}

domínio e infraestrutura de telecomunicação, ausência de suporte no auxílio dos beneficiados por esta modalidade de ensino, tanto docentes quanto alunos e outros (MOORE; KEARSLEY, 2011).

A Educação a Distância (EaD), apresenta similaridades com o ensino remoto, pois ambos utilizam tecnologias como fonte de recursos didático pedagógicos (COSTA, 2020). Porém, cabe salientar que são métodos diferentes. Segundo, Daros (2020), a diferença entre eles está centrada no caráter emergencial e temporário da solução encontrada para as atividades pedagógicas no contexto do ensino remoto em cenário de pandemia. A educação à distância $(\mathrm{EaD})$ tem a finalidade da interação online (síncrona e assíncrona) e é uma estratégia de ensino mais duradoura. A experiência é desenvolvida e direcionada para aplicação na internet, o que demanda um planejamento detalhista e voltado aos meios digitais e com encontros presenciais em determinados pontos do percurso formativo do discente. Ainda que na EAD as aulas possam, ser $100 \%$ gravadas é comum as videoconferências (momentos síncronos) com o tutor para esclarecer dúvidas e há a figura do professor conteudista que elabora os materiais didáticos. Geralmente, os materiais didátios e/ou paradidáticos tendem a ser padronizados e feitos em larga escala para atender a proposta pedagógica do curso, o Projeto Político Pedagógico (PPC). No ensino remoto emergencial, a interação entre discentes e docentes tende a ocorrer a distância com aulas aulas realizadas ao vivo (momentos síncronos) e atividades realizadas sem a presença do professor (momentos assíncronos), como exemplos, fichamentos de textos, vídeos complementares aos momentos síncronas, dentre outras estratégias. Um ponto em comum entre a Educação a Distância $(\mathrm{EaD})$ e o Ensino Remoto Emergencial se dá pela grande centralidade das Tecnologias de Informação e Comunicação (TICs).

Alguns autores descrevem os perfis dos estudantes da EaD, como adultos, trabalhadores, que procuram uma aprendizagem mais guiada para a prática, dispõem de experiências de vida e de trabalho, gostam de ter autoridade sobre seus atos e compreendem essa modalidade como uma modalidade bastante farta e com enormes possibilidades de estudos, não oferecida a eles enquanto mais novos (PETERS, 2006; DIAS; LEITE, 2010).

Deve-se traçar, também, outros perfis quando se pensa no estudante usufruidor de tecnologias. Silva (2012) utiliza as expressões nativos digitais e imigrantes digitais para delinear alguns comportamentos dos adultos. De forma geral, os primeiros sujeitos digitais 


\section{Impacto do ensino remoto na formação dos discentes do curso de engenharia agronômica: UEMG Unidade Ituiutaba - MG}

surgiram após 1980, estes têm conhecimentos tecnológicos, outorgam confiabilidade à rede, a usam para encontros virtuais e eventos desse cunho (CAMILO; MULLER, 2019).

Todavia, pessoas que nasceram até o ano de 1980 ainda estão aprendendo a lidar com a tecnologia, realizam um passo de cada vez, de forma simples e seguem sempre uma sequência linear. Entendem o encontro com outros como particular, optam por se conhecerem pessoalmente e só assim se verem virtualmente. Nestes comportamentos dessemelhantes entre estes dois públicos citados, fica nítido as possíveis diferenças de aprendizado entre idades distintas, e ao se levar em consideração que há formas de aprendizagem e portanto, que as pessoas não aprendem de forma semelhante (SILVA, 2012).

Outro desafio enfrentado pelo ensino remoto e o EaD, segundo Fiorentini (2003), é a criação de materiais didáticos, entende-se que o léxico precisa de um cuidado relevante, considerando que as pessoas que terão acesso aos conteúdos, são públicos diferentes. Sathler (2020) diz que a matriz ou modelo, de ensino oferecido durante a pandemia da COVID-19, é o ensino à distância de emergência e de péssima qualidade, o qual teve princípios importantes sufocados, como o planejamento de caminhos diferentes para a aprendizagem, que faz com que os alunos não participem ativamente.

O ensino e aprendizagem que já eram ruins antes da pandemia, por conta da à impotência do regime de ensino que começa na educação básica e vai até a educação superior, penará para muito mais com o modelo implementado, modelo tecnológico emergencial na era da COVID-19 (SATHLER, 2020).

\section{A infoexclusão}

A tecnologia vem provocando inúmeras mudanças na sociedade contemporânea, e a adequação a qual as pessoas vêm passando para poderem acessar a toda esta tecnologia é sem dúvidas um dos maiores movimentos já existente na humanidade (SANTOS, MENDES; AMARAL, 2006, p. 20). Entre estes que têm condições de usufruir toda esta inovação, encontra-se também muitos sujeitos que não tem oportunidade de lograr nesta modernização.

Ao pensar sobre a infoexclusão sua proximidade com o desequilíbrio social, pode-se considerar também o modo como o público dos nativos digitais pode sofrer com esta problemática. Tais jovens e crianças que se desenvolvem ao mesmo tempo em que o movimento da tecnologia, pode sofrer com a oferta de menos oportunidades e maiores dificuldades de valia dos benefícios quando separamos as classes sociais baixas e famílias de classes altas. (LIVINGSTONE; HELSPER, 2007). 


\section{Impacto do ensino remoto na formação dos discentes do curso de engenharia agronômica: UEMG Unidade Ituiutaba - MG}

A infoexclusão, no âmbito da sociedade conectadas em redes está relacionada a dois grandes recortes iniciais: I- chegada da Internet; II - pelo crescente desenvolvimento das Tecnologias da Informação e Comunicação, as TICs ${ }^{3}$. No geral, a infoexclusão remete a ausência de oportunidades de acesso individual ou de determinados grupos, decorrentes da existência de equipamento e de ligações à rede digital, mas que o acesso é limitado ou inexistência, como exemplo, a internet. O segundo relaciona-se com o ultrapassar de um limiar mínimo de desconhecimento sobre informática, que permita ao indivíduo ou determinados grupos operar com um computador ou outros meios que remeta as Tecnologias de Informação e Comunicação (TICs). A infoexclusão remete a pobreza econômica, exclusão social. Na sociedade da comunicação e informação, a infoexclusão pode indicar uma amplificação das desigualdades sociais. A ausência de oportunidades ou sua existência de forma limitada, o que priva parte dos grupos sociais ou indivíduos de terem acesso ao padrão de vida vigente em determinadas sociedades, como exemplo, o acesso a um conjunto de redes, dentre elas, a internet; II- a infoexclusão pode apontar as trajetórias de famílias e indivíduos que não têm a capacidade ou oportunidade de participar plenamente da sociedade a que pertencem - uma sociedade em redes. Entende se que TICs (Tecnologias da informação e comunicação) trata de um conjunto de recursos tecnológicos interligados entre si, que proporcionam, por meio das funções de hardware, software e telecomunicações, a automação e comunicação dos processos de negócios, da pesquisa científica e de ensino e aprendizagem, dentre outros.

Não obstante, acreditar que a infoexclusão se explicita na totalidade de fatores que são unicamente socioeconômicos e escolares, estar-se-ia limitando causas muito maiores. Considerando as gamas, gênero e idade, tendo em conta outras dimensões que são verdades de exclusão tecnológica, o público de maior subdesenvolvimento é o foco desta desigualdade social, que retrata dificuldades motivacionais e de conhecimento, mostrando problemas complexos que vão além das dissemelhanças entre quem é adepto, ou não, à inovação

\footnotetext{
${ }^{3}$ Há diversos exemplos sobre as Tecnologias da Informação e Comunicação, as TICS, mas poderemos citar: Computadores pessoais (PCs, personal computers); Câmeras de vídeo e foto para computador ou Webcams; Gravação doméstica de CDs e DVDs; Suportes para guardar e portar dados como discos rígidos ou hds, cartões de memória, pendrives, entre outros; Telemóveis ou celulares; Tv por Assinatura, TV a cabo, TV por antena parabólica, TV por parabólica, TV digital; Correio eletrônico (e-mail) e as Listas de discussão (mailing lists); Internet, a World Wide Web, websites e home pages, quadros de discussão (mensage boards); Streaming, podcasting, wikipedia entre outros; Tecnologias digitais de captação e tratamento de imagens e sons (Vimeo, Youtube, last Fm); Captura eletrônica ou digitalização de imagens por meio de scaners; A fotografia, cinema, vídeo e som digital (TV e rádio digital); Tecnologias de acesso remoto: Wi-Fi, Bluetooth, RFID, dentre outros.
} 


\section{Impacto do ensino remoto na formação dos discentes do curso de engenharia agronômica: UEMG Unidade Ituiutaba - MG}

(MEDINA, 2005). Essa heterogeneidade entre os grupos é destacada por (CABECINHAS, LIMA E CHAVES, 2006),

(...) é necessário ter em conta que cada grupo é heterogéneo, sendo constituído por uma grande diversidade de indivíduos, com diferentes percursos e experiências de vida e pertencendo a grupos com diferentes posicionamentos na estrutura social. (p. 7).

Outro fator contribuinte para exclusão tecnológica é a falta de infraestrutura e telecomunicação.

Ao caracterizar uma vivência que se situa no nível individual e também no nível social ou até no nível geográfico, a infoexclusão deduz o restringimento ao acesso e as comunicações no espaço virtual (KENISTON; KUMAR, 2004). Contudo, ao criar-se um espaço para infoexclusão, contribui-se também para criação do fenômeno chamado exclusão educacional, a qual já se faz presente por outros meios.

\section{Metodologia}

Ao propor e desenvolver um estudo sobre os impactos do ensino remoto, optou-se pela abordagem metodológica qualitativa e quantitativo. Segundo Oliveira, 2010:

A prática de combinar técnicas de análise quantitativa com técnicas de análise qualitativa proporciona maior nível de credibilidade e validade aos resultados da pesquisa evitando-se, assim o reducionismo por uma só opção de análise. (OLIVEIRA, 2010, p. 39).

$\mathrm{Na}$ produção de evidências a entrevista se configurou como principal instrumento (ou técnica) do método. Para realizá-la, não há uma única receita ou diretriz. Contudo, devese salientar que as entrevistas foram realizadas em contexto de pandemia utilizando as Tecnologias de Comunicação e Informação. Ocorreram entrevistas semiestruturadas (com questões postas) e entrevistas abertas, mas com enfoque no tema do ensino remoto emergencial. Importante apresentar aqui algumas observações que orientaram a conduta dos pesquisadores no decurso da pesquisa:

I- não há neutralidade do pesquisador no processo de aquisição de evidências baseadas em entrevistas; isso fica claro na escolha do tipo de entrevista, e até mesmo na opção por qualquer outro instrumento para a coleta de dados, bem como na elaboração das questões e na seleção dos informantes;

RIET- ISSN 2676-0355, Dourados, v. 2, n. 2, p. 264 a 285, jan./jun., 2021 


\section{Impacto do ensino remoto na formação dos discentes do curso de engenharia agronômica: UEMG Unidade Ituiutaba - MG}

II- a entrevista apresenta limites: de fato, não há nenhum método que dê conta de abranger satisfatoriamente todas as dimensões de uma determinada realidade. A entrevista não representa somente uma técnica de coleta de dados, mas é parte integrante da construção do objeto de estudo. Ao trabalhar com entrevistas, o pesquisador deve respeitar os princípios éticos;

III- a entrevista não deve ter uma estrutura rígida: embora haja questões previamente definidas, elas podem sofrer alterações, em conformidade com o andamento da investigação. Nesse sentido, é preferível que o pesquisador se disponha a trabalhar com perguntas abertas e um roteiro flexível. A temporalidade do contato entre informante e pesquisador é um elemento que pode influenciar na qualidade das informações e das evidências coletadas ao longo da pesquisa, por isso, é importante reservar um longo tempo para a realização da entrevista;

IV- durante a realização da entrevista, é importante fazer uso de um diário de campo para o registro de anotações que podem ser utilizadas como complemento das informações obtidas; V- ao longo das entrevistas, determinados elementos podem evocar a memória, tais como fotografias, que auxiliam os entrevistados a se lembrarem de fatos específicos;

VI- construção de fichas que organizem e orientem as análises das fontes orais é também recurso útil, entre outros.

Há um consenso entre os pesquisadores que tratam da produção de evidências baseadas em fontes orais, que atribui o sucesso das entrevistas mais à obtenção da confiança dos entrevistados por parte dos pesquisadores, que propriamente às técnicas empregadas. A riqueza do material coletado, analisado e interpretado dependerá dessa relação de confiança. É preciso lembrar que as relações de pesquisa, mesmo que distintas das demais trocas existentes no contato humano, não deixam de ser uma relação social e, nesse sentido, não deixam de exercer, sobre os resultados da investigação, os efeitos relacionados aos contextos de poder e submissão na relação entre pesquisador e pesquisado.

O contexto empírico para realização deste estudo foi a Universidade do Estado de Minas Gerais (UEMG), Unidade de Ituiutaba, curso de Engenharia Agronômica. A UEMG possui aproximadamente 22 mil alunos (as) distribuídos em 20 unidades espalhadas por 16 cidades de Minas Gerais e conta com 118 cursos de graduação, 41 de pós-graduação e 15 


\section{Impacto do ensino remoto na formação dos discentes do curso de engenharia agronômica: UEMG Unidade Ituiutaba - MG}

polos de ensino a distância. A unidade ${ }^{4}$ de Ituiutaba foi estadualizada no dia 3 de abril de 2014 através do Decreto $N^{\circ} 46.478$ e conta atualmente com mais ou menos 2.600 alunos distribuídos em treze cursos. O curso de Engenharia Agronômica conta com um total de 345 alunos distribuídos nos cursos integral e noturno.

A coleta de dados consistiu na aplicação de um questionário contendo questões abertas e fechadas, enviado via redes sociais. Um total de 158 alunos respondeu ao questionário, o que corresponde a 45,8\% dos alunos matriculados no curso. A presente pesquisa teve consentimento dos discentes, onde se firmou o compromisso de assegurar sigilo quanto a identificação dos sujeitos participantes. $\mathrm{O}$ desenvolvimento do trabalho, contou com dois momentos e ferramentas metodológicas diferentes. O primeiro momento consistiu na aplicação do questionário aos discentes do curso de Engenharia Agronômica, elaborados na plataforma Google Docs. Já o segundo momento consistiu na análise, interpretação e discussão dos dados. As questões objetivas (questionário) foram tabuladas no Excel e as evidências empíricas foram completadas com entrevistas abertas e semiestruturadas.

\section{Resultados e Discussão}

\section{Identificação do perfil dos discentes}

Este tópico buscará detalhar o perfil dos discentes que contribuíram na colaboração desta pesquisa. Os respondentes estão distribuídos em todos os semestres do curso que vão desde o $1^{\circ}$ período até o $10^{\circ}$ período. Dos 158 alunos participantes, $80(50,6 \%)$ são alunos do curso integral, $63(39,9 \%)$ corresponde aos matriculados no noturno e $15(9,5 \%)$ tratam-se daqueles que não possuem um período definido, participando de variadas turmas para cursarem as disciplinas remanescentes.

Ao considerar a participação de apenas 45,8\% dos alunos, essa ausência de respostas pode ser atribuída a dois segmentos/possibilidades: a primeira a ser pensada trata-se, que os alunos tiveram acesso a plataforma, mas se negaram a participar; a segunda possibilidade estaria pautada no fato de muitos alunos não terem acesso às informações, já que utilizamos as TICs como ferramentas para a veiculação do questionário. Sendo assim, a própria

\footnotetext{
${ }^{4}$ Até a sua estadualização a UEMG Unidade Ituiutaba pertencia a Fundação Educacional de Ituiutaba, que foi instituída em 1963, com a finalidade de criar, instalar e manter, sem fins lucrativos, escolas de ensino fundamental, médio e superior.
} 


\section{Impacto do ensino remoto na formação dos discentes do curso de engenharia agronômica: UEMG Unidade Ituiutaba - MG}

metodologia de coleta de dados, que era a possível para o momento, pode ser entendida como um processo inicial de exclusão.

De acordo com Hodges (2020) a educação remota eficaz exige um grande investimento e apoio ao aluno, o qual leva tempo para ser identificado e construído. Uma vez que não programado e pensado o mesmo tende a excluir os discentes do processo participativo.

Hodges, (2020, p. 2) ainda cita que:

Uma experiência de aprendizado online bem planejada é muito diferente dos cursos oferecidos online em momentos de crises ou de desastres. Escolas e universidades que trabalham para manter o ensino durante a pandemia do COVID-19 devem entender essas diferenças ao avaliar esse ensino remoto de emergência.

Foi indagado aos discentes se a pandemia teve influência na sua vida pessoal, no que concerne ao processo de moradia. A partir das respostas observou-se que anterior a este momento vivenciado, 77,8\% dos pesquisados residiam na cidade de Ituiutaba, 17, 7\% destes em outras cidades, uma minoria de $2,5 \%$ na zona rural e 1,9\% se encontravam em outras situações. Mas essa realidade foi alterada em decorrência ao processo de isolamento social, onde alguns alunos tiveram que retornar a suas cidades de origens ou retornarem ao meio rural.

Como mencionado acima alguns alunos são oriundos de outras cidades ou residem na zona rural, onde não possuem instituições públicas de ensino superior e estes necessitam se deslocar para cidades maiores em busca de oportunidades e de aprimorar seus conhecimentos em cursos de graduação gratuitos.

\section{Posicionamento dos discentes quando a modalidade ensino remoto}

No início da pandemia quando as atividades presenciais da universidade em questão foram suspensas, muitos rumores e posicionamentos sobre o retorno em modalidade remota, foram discutidos informalmente através de redes sociais como: grupos de WhatsApp, Facebook, Instagram, e uma grande parte dos discentes, entendiam a necessidade de retorno de forma remota e aprovavam, e uma outra parte não era favorável. Expectativas tanto positivas quanto negativas foram criadas em relação a tal modalidade e estas no decorrer do retorno das atividades não presenciais vieram a sofrer, ou não sofreram mudanças de opiniões segundo os pesquisados. 


\section{Impacto do ensino remoto na formação dos discentes do curso de engenharia agronômica: UEMG Unidade Ituiutaba - MG}

Ao se falar em expectativas positivas podemos citar apontamentos de discentes no questionário, em relação às questões de cuidado com a saúde em tempos de isolamento social:

Diante da atual situação em que vivemos, em relação a pandemia, essa é ainda a melhor opção para não nos colocarem em risco, não podemos ter aula presencial nesse momento. Sendo assim, me sinto mais confiante que estamos mais seguros dessa forma (Respondente $\mathrm{n}^{\circ} 43$ ).

Outros discentes apontam de forma positiva a não perda do semestre letivo, bem como a conciliação do trabalho com os estudos. Além disso, foi levantado que as empresas, na atualidade, buscam profissionais capacitados para trabalhar com as tecnologias como é mensurado nas respostas abaixo:

Embora, com algumas dificuldades e falta de algumas práticas, é a forma que temos para não perder muito tempo, sendo assim, estou satisfeito. Fico feliz por a faculdade poder realizar esse ensino remoto, ajudando os alunos a não perder o semestre, consigo estudar e trabalhar ao mesmo tempo (Respondente $\mathrm{n}^{\circ} 157$ ).

Negativo na parte de aulas de laboratórios e experimentos de campo e positivo na parte de emprego, porque as empresas se adaptaram muito rápido neste novo cenário, e com certeza deve ser o futuro fazer até consultoria por meio de celulares, tablets e etc (Respondente $\mathrm{n}^{\circ} 107$ ).

Camillo e Muller (2019, p.21) enfatizam que as TICs ajudam "a promover novas formas de interação e construção do conhecimento, estimulando os indivíduos a desenvolverem a capacidade de reflexão, debater, intervir e de fazer escolhas conscientes dentro da sociedade em que vivem".

Apontou-se como cenários negativos: falta de aulas práticas, defasagem nos sistemas de comunicação, falta de apoio psicossocial, excesso de atividades. Em meio a estas discussões ressalta-se o desabafo de um discente:

Está sendo uma frustração, pois não temos o devido preparo, não sei como os professores vão avaliar os alunos com apresentação e provas on-line, pois na nossa cidade a internet não funciona como deveria é isso é algo preocupante. $\mathrm{E}$ as aulas práticas como ficarão? (Respondente $\mathrm{n}^{\circ} 112$ ).

Na Figura 1, observa-se que $23,4 \%$ dos pesquisados permaneceram com as expectativas iniciais com relação ao ensino remoto, de forma positiva, 39,9\% se frustraram em relação a esta modalidade de ensino e $26,6 \%$ mantiveram suas opiniões negativas em

RIET- ISSN 2676-0355, Dourados, v. 2, n. 2, p. 264 a 285, jan./jun., 2021 


\section{Impacto do ensino remoto na formação dos discentes do curso de engenharia agronômica: UEMG Unidade Ituiutaba - MG}

relação ao ensino. Entretanto, aproximadamente 10,1\%, apontaram estar surpreendidos de forma positiva com o atual cenário proposto pela universidade.

Figura 1: Opiniões positivas e negativas quanto ao ensino remoto.

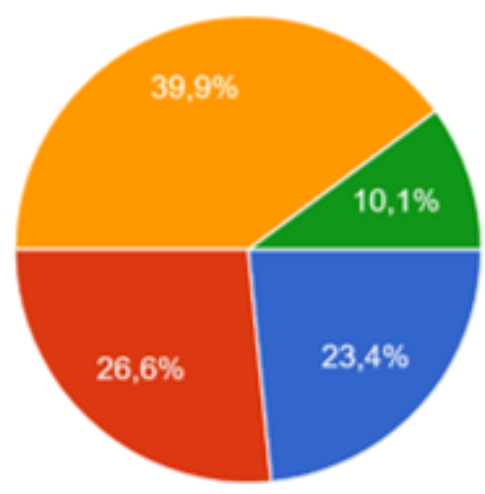

Permanece nas expectativas iniciais (Positivas).

Permanece nas expectativas iniciais (Negativas).

Năo tenho as mesmas expectativas iniciais, me frustrei.

Nāo tenho as mesmas expectativas iniciais, me surpreendeu de forma positiva.

Fonte: os autores (2020).

As frustrações estão relacionadas com determinados fatores tais como: atividades incompatíveis com o conteúdo abordado, falta de aulas práticas, dificuldade de comunicação rápida com os docentes, falta de acesso em tempo real das aulas e devido à instabilidade da internet.

Outro ponto bastante elencado, é em relação a demanda de atividades assíncronas ${ }^{5}$ que são enviadas pelos educadores. Muitos discentes não estão conseguindo conciliar a demanda de atividades com suas rotinas, visto que alguns trabalham, outros cuidam de familiares, alguns estão acometidos a doenças e assim por diante.

Sendo assim, para exemplificar tais frustações cita-se como exemplo:

Antes entendia como fator positivo, hoje digo que é frustação, entendo que não é culpa dos professores e nem nossa, é um momento delicado para todos e ambos estão tentando lidar da melhor forma mas está havendo uma sobrecarga nas atividades assíncronas e acabando por prejudicar o nosso desempenho (Respondente, $\mathrm{n}^{\circ} 17$ ).

Entender e enfrentar as dificuldades vivenciadas pelos alunos é algo que demanda uma experiência e sensibilidade muito grande. Além dos fatores supracitados outras dificuldades foram citadas, sendo: excesso de atividades assíncronas, dificuldade de

\footnotetext{
${ }^{5}$ As aulas no curso de Engenharia Agronômica voltaram distribuídas em 50\% de aulas síncronas, que são s aquelas em que é necessária a participação do aluno e professor no mesmo instante e no mesmo ambiente nesse caso o ambiente virtual. E 50\% de aulas assíncronas que são aquelas que não é necessário que os alunos e professores estejam conectados ao mesmo tempo para que as tarefas sejam concluídas
} 


\section{Impacto do ensino remoto na formação dos discentes do curso de engenharia agronômica: UEMG Unidade Ituiutaba - MG}

concentração nas aulas síncronas, cansaço mental e esgotamento emocional, crises de ansiedade, falta de preparo psicológico, problemas com acesso as aulas gravadas. Além disso, $5,1 \%$ dos discentes afirmaram que não conseguem ter acesso aos sistemas propostos pela universidade, seja por falta de aparelhos eletrônicos ou por não terem domínios das tecnologias.

Segundo a Secretária de Educação do Estado de Minas Geias (2020) foi realizado um balanço sobre o modelo, e este não é promissor. Uma vez que tal ensino não contempla todos os alunos, principalmente aqueles que vivem em realidades mais carentes, tornando assim um modelo desigual e excludente.

Em relação ao processo de ensino e aprendizagem, segundo os pesquisados, $44,3 \%$ destes afirma que o tipo de modalidade adotada pela UEMG atrapalha consideravelmente a aprendizagem dos mesmos e 39,2\% se mantem na vertente que o mesmo tem influência direta de forma negativa na aquisição de conhecimento do curso. Há uma minoria de 16,5\% que afirma não haver interferência no ensino e aprendizagem (Figura 2)

Figura 2: Opiniões em relação ao processo de ensino e aprendizagem.

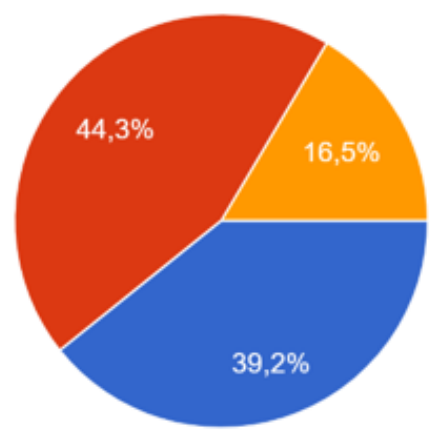

A presente modalidade atrapalha o ensino e a aprendizagem.

A presente modalidade atrapalha consideravelmente o ensino e a aprendizagem.

A presente modalidade não atrapalha o ensino e a aprendizagem.

Fonte: os autores (2020)

Sathler (2020) em suas discussões, afirma que o processo de ensino e aprendizagem estava em crise no momento pré-pandemia, devido à ineficácia do processo de ensino permeando desde a educação básica até o ensino superior, e que no atual cenário sofrerá mais ainda com o novo modelo tecnológico emergencial adotado em tempos de isolamento social divido o COVID-19 (p.5).

Com relação a continuidade do ensino remoto, no período que perdurar a pandemia, uma maior porcentagem dos discentes concorda com a continuação da atual modalidade

RIET-ISSN 2676-0355, Dourados, v. 2, n. 2, p. 264 a 285, jan./jun., 2021 


\section{Impacto do ensino remoto na formação dos discentes do curso de engenharia agronômica: UEMG Unidade Ituiutaba - MG}

$(55,1 \%)$, no entanto a outra parte $(44,9 \%)$ aponta que é inviável visto que influenciará diretamente na qualidade de ensino, pois as práticas presenciais do curso estão totalmente suspensas sendo estas substituídas por algo que não tem a mesma eficácia quanto o ensino presencial. Com relação a essa situação os discentes afirmam que:

Ficamos prejudicados, com a oferta de matérias que teriam bastante prática e por ser remoto não vamos ter. A prática é primordial ao aprendizado dos futuros agrônomos (Respondente $\mathrm{n}^{\circ} 135$ ).

Porque geralmente as aulas práticas são momentos em que mais aprendemos, onde colocamos em prática todo conhecimento adquirido em sala de aula, e a falta delas nos prejudicará (Respondente $\mathrm{n}^{\circ} 18$ ).

O impacto de uma formação teórica sem a vivência de campo, faltando qualificação para um mercado de trabalho cada vez mais exigente em questão de experiência (Respondente $n^{\circ} 158$ ).

Após as descrições acima, evidencia-se o quanto os discentes entendem a importância da parte prática do curso em questão, sendo essa enfatizada pela grande maioria dos entrevistados. Porém, outros discentes apontam aspectos positivos mesmo sem aulas práticas, como pode-se observar abaixo:

Positivo, já fizemos bastante aulas práticas então tenho uma noção do que podemos fazer nas matérias futuras, e isso não será o curso todo (Respondente $\mathrm{n}^{\circ} 26$ ).

Quem faz a faculdade é o aluno, então se o aluno se esforçar terá sim impacto positivo (Respondente $\mathrm{n}^{\circ} 60$ ).

Salienta-se, que os docentes já estão elaborando propostas, para serem aplicadas póspandemia, como forma de suprir a ausência das aulas práticas, através de eventos, visita técnicas, trabalhos de campo e minicursos no âmbito de componentes curriculares com abordagens mais práticas. Nesse ponto Bezerra (2020) afirma que:

É preciso ter expectativas realistas diante de soluções diversas encontradas, compreendendo a importância de adotar alternativas para esse momento, e sobretudo alertando que estas não suprirão todas as necessidades acadêmicas esperadas e previstas nos currículos (BEZERRA, 2020 p. 12).

Seguindo a mesma perspectiva, Ely (2020) afirma que:

"Há consenso entre especialistas que o ensino remoto não substitui o presencial, mas, ao menos, contribui para minimizar os danos causados pela suspensão das aulas. (...) o afastamento do ambiente escolar deixará

RIET- ISSN 2676-0355, Dourados, v. 2, n. 2, p. 264 a 285, jan./jun., 2021 


\title{
Impacto do ensino remoto na formação dos discentes do curso de engenharia agronômica: UEMG Unidade Ituiutaba - MG
}

sequelas que precisam ser amenizadas mesmo [a]distância." (ELY, 2020, S/N.).

Mesmo diante da atual realidade vivida pelos estudantes do curso de Engenharia Agronômica, 74,1\% dos entrevistados sentem-se inclusos na modalidade ensino remoto, sendo que $25,9 \%$ se sentem exclusos, sejam pelas dificuldades de acesso aos meios tecnológicos ou por portarem necessidades especiais e não estarem amparados pela universidade (ressalta-se que não foram mensurados junto aos pesquisados quais necessidades especiais os mesmo apresentam), neste caso (1,3\%) destes, segundo o levantamento.

Aos discentes que se sentem exclusos, sejam por quaisquer motivos citados acima, torna-se um fator preocupante, uma vez que o espaço da universidade deveria ser um ambiente de inclusão e não exclusão, visto que as políticas públicas, em suas entrelinhas, trazem tais discussões, as quais configuram um ambiente que deverá dar acesso a todos, independentemente de classe social, gênero e etnia.

Stevanim, 2020 afirma:

\begin{abstract}
$\mathrm{O}$ ensino remoto nas universidades e nas escolas brasileiras desconsidera a diversidade de alunos que temos. As universidades públicas têm sobretudo a missão de serem inclusivas. Quando elas decretam o ensino remoto, deixam de pensar nesse propósito de inclusão, porque excluem pessoas que não têm acesso (STEVANIN, 2020 p. 14).
\end{abstract}

Mesmo que seja para uma minoria, a implantação do ensino remoto emergencial, tem deixado marcas, e a exclusão digital é uma das principais, o que acaba dificultando a adoção de medidas síncronas e assíncronas. Apontando para uma modalidade que necessita ser repensada, analisada, e reestruturada, uma vez que venha ser ofertada com menor impacto possível, pois tal cenário está sendo configurando, como uma crise dentro da crise.

Segundo Stevanim, (2020) a atual realidade aponta para um cenário descriminalizador em relação as políticas emergenciais adotas, uma vez que se torna mais evidente as desigualdades sociais, educacionais e regionais. O autor salienta sobre as desigualdades estruturais:

"Emergiram à superfície nesse momento de pandemia. As políticas adotadas para a educação, como a implantação de educação remota mediada por tecnologias, foram pensadas de forma alheia a essa desigualdade, sem trazer caminhos de solução dos problemas estruturais. E elas não deram certo (STEVANIM, 2020, p. 5).

RIET- ISSN 2676-0355, Dourados, v. 2, n. 2, p. 264 a 285, jan./jun., 2021 


\section{Impacto do ensino remoto na formação dos discentes do curso de engenharia agronômica: UEMG Unidade Ituiutaba - MG}

Ainda, permeando as discussões sobre inclusão e exclusão, registrou-se que 58,9\% dos entrevistados, mesmo com as dificuldades vivenciadas, não consideraram o trancamento parcial ou o abandono total do curso e $41,1 \%$ destes consideraram o trancamento parcial ou abandono devido ao atual cenário. Ressalta-se que, por mais que parte dos discentes já tenha cogitado a possibilidade de abandono ou o trancamento parcial/total do curso de Engenharia Agronômica, para a maioria a busca pelo sonho de concluir o ensino superior é cada vez mais almejada.

No atual processo, a colaboração por ambas as partes, discentes/ docentes é primordial, na busca por um ensino de qualidade menos excludente, evitando situações de vulnerabilidade, almejando por um equilíbrio emocional no enfrentamento dos desafios, de forma a não tornar o processo desanimador e intolerável. Nesse sentido, Torres (2020) afirma que:

Todos os esforços são valorizados neste momento (...) até as ações voltadas para redução de danos no processo de ensino e aprendizado. O que essa urgência não pode deixar de perceber é o aumento da vulnerabilidade de um grande número de discentes. O processo não pode ser ainda mais cruel que o momento que estamos vivenciando, atropelando o sonho do ensino superior em saúde de milhares de seres humanos que não apenas não conseguem acompanhar as aulas por falta de tecnologia, mas também por falta de alimento à mesa, por falta de equilíbrio emocional e cognitivo. (TORRES, 2020, p.8).

Nos sentimentos em relação a atual modalidade de ensino, se encontram respostas que expressam sentimentos de ódio, desespero, desequilíbrio emocional, falta de conhecimento e de domínio da plataforma e dos meios de comunicação, estresse e cansaço físico emocional, por passarem horas em frente à tela de celular/computador, como pode ser constatado na resposta apresentada pelo discente quando indagado sobre os sentimentos com relação ao ensino remoto.

Pessimismo, angústia, vazio, frustração, desapontado...Entendo que por circunstância da pandemia é o único modo de estudar atualmente, mas está ficando inviável porque eu assim como muita gente trabalha e está tendo muita atividade pra ser entregue em um curto espaço de tempo. (Respondente $\mathrm{n}^{\circ} 06$ ).

As manifestações resultantes das respostas dos universitários são considerações e apontamentos que precisam ser discutidos pelas autoridades responsáveis pela universidade, uma vez que envolvem questões sociais, emocionais/comportamentais dos indivíduos afetados. Manifestações emocionais como as apresentadas precisam ser consideradas para

RIET- ISSN 2676-0355, Dourados, v. 2, n. 2, p. 264 a 285, jan./jun., 2021 


\section{Impacto do ensino remoto na formação dos discentes do curso de engenharia agronômica: UEMG Unidade Ituiutaba - MG}

não tornar o ensino remoto uma ferramenta desmotivadora ao curso de engenharia agronômica, possibilitando assim a evasão desses alunos. Segundo Stevanim (2020), há de se pensar, com relação à educação pública, uma contribuição para construir uma sociedade com pessoas que livres e autônomas.

\section{Considerações Finais}

Pretende-se aqui esboçar alguns apontamentos finais, numa perspectiva de compreender os resultados apresentados na verificação empírica. Neste sentido, é gritante o quão é mencionado nas respostas dos discentes, a falta que faz as aulas práticas, tornando prejudicial o entendimento dos alunos, pois os mesmos sentem extrema dificuldade de imaginar a teoria no contexto real. Várias são as metodologias empregadas pelos docentes de forma a suprir esta demanda, mas evidenciou-se que as aulas práticas presenciais são consideradas indispensáveis na formação de um bom profissional.

Por mais que a Universidade tenha buscado meios de propor o ensino remoto de qualidade, em que a exclusão seja mínima, ainda não foi possível alcançar o patamar ideal de atendimento a todos, nas mais diversas circunstâncias que permeiam o espaço de aprendizagem, uma vez que a mesma se trata de uma universidade pública onde ingressam alunos de diferentes classes sociais, e de diferentes condições de acesso às TICs.

Entretanto, os impactos sociais da pandemia, que vai além da questão do ensino e aprendizagem e questões de natureza biomédica e epidemiológica, provocando efeitos, também, nas esferas social, econômico, político, cultural e histórico. No decurso da pandemia os discentes têm vivenciado distintos problemas pessoais, e se sentem frágeis psicologicamente a esta modalidade, dentre eles, o cenário novo de pandemia, a distância da vida em/na comunidade, a dificuldade de frequentar laboratórios, a infoexclusão e a perda de familiares, de amigos, etc. Importante lembrar que a pandemia não alterou apenas os meios e modos de vida, mas amplificou as perdas de vida: desde o início da pesquisa até junho de 2021, um total de 461 mil brasileiros morreram de Covid $19^{6}$. Se considerarmos que em 2010, Ituiutaba (MG) tinha 105.255 habitantes (IBGE, 2010), “quatro Ituiutabas

\footnotetext{
${ }^{6}$ Fonte: JHU CSSE COVID-19 Data e Our World In Data, 04 de junho de 2021. Entretanto, considerando que os dados são atualizados diariamente os números de mortos podem ser consideravelmente maior para o ano de 2021 a partir de uma letargia em imunizar a população, dentre outros fatos, pela dificuldade do governo do presidente Jair Messias Bolsonaro (2019 até a atualidade) em elaborar estratégias efetivas para imunizar a população (vacinação em massa) e defesa por parte desse governo do chamado tratamento precoce do Covid 19 cientificamente considerado ineficaz como exemplo, o uso de medicamentos como a hidroxicloroquina.
} 


\section{Impacto do ensino remoto na formação dos discentes do curso de engenharia agronômica: UEMG Unidade Ituiutaba - MG}

sumiram em um intervalo de um ano". Considerando que todas as vidas importam, entretanto, também é importante pontuar os impactos econômicos da pandemia na vida dos discentes: pais provedores financeiramente de seus lares que perderam seus empregos, a dificuldade dos discentes em conseguir estágios remunerados, dentre outros fatos modificado pelo atual cenário de pandemia. Os dados anteriormente expostos amplificam a infoexclusão,

Grosso modo, para os discentes participantes da pesquisa os pontos negativos sobre o Ensino Remoto Emergencial se sobrepõem aos pontos positivos. A infoexclusão, a distância física da vida acadêmica convencional e a ausência de aulas práticas contribuem para a ampla avaliação negativa do ensino remoto.

Sendo a modalidade de ensino remoto a mais indicada e de extrema necessidade no cenário atual, e baseando-se nos aspectos analisados até o presente momento, ainda não é possível mensurar o tamanho impacto causado na formação acadêmica e nem mesmo em relação às questões sociais e psíquicas dos discentes do curso de graduação em Engenharia Agronômica, entretanto, pode-se afirmar que qualquer tentativa de fortalecer outras modalidades de ensino, como exemplo, o EaD pós pandemia representará no mínimo uma ampliação da precarização do ensino, sobretudo para cursos com matriz curricular recheada de aulas práticas, como é o caso do Curso de Agronomia. O Ensino Remoto Emergencial deve ser entendido como um fenômeno pontual e passageiro em contexto de pandemia, mas também não há justificavas plausíveis para sua permanência em cenários em que seja possível a aglomeração de docentes, discentes, servidores públicos, técnicos laboratoriais e a comunidade em geral, considerando que a universidade pública se sustenta no tripé ensino, pesquisa e extensão.

\section{Referências}

BUARQUE, Aurélio. Novo Aurélio Século XXI: o dicionário da língua portuguesa. $3^{\mathrm{a}} \mathrm{ed}$. totalmente rev. e ampl. Rio de Janeiro: Nova Fronteira; 1999.

CAMILLO, Cintia Morales; MÜLLER, Liziany. A usabilidade de um ambiente virtual de ensino e aprendizagem: um estudo sobre o Moodle da UFSM. Temática - Revista eletrônica de publicação mensal. Santa Maria, v. 15, p. 14-19, 2019.

CABECINHAS, Rosa; LIMA, Marcos Eugênio Lima; Chaves, Antônio. Identidades nacionais e memória social: hegemonia e polêmica nas representações sociais da história. In: MIRANDA Joana (org.). Identidades Nacionais em Debate. Oeiras: Celta, 2006.

CASTELLS, Manuel. A sociedade em rede. São Paulo, Paz e Terra. 1999. 


\section{Impacto do ensino remoto na formação dos discentes do curso de engenharia agronômica: UEMG Unidade Ituiutaba - MG}

CASTELLS, Manuel. Networks of Outrage and Hope - Social Movements in the Internet Age. Cambridge: Polity Press, 2012

DAROS, THUINIE. Covid-19 impulsiona uso de metodologias ativas no ensino a distância.

Desafios da Educação, São Paulo, ano 31, n. 25, 10 marc. 2020. Parte integrante da edição 650.

GOMES, Elisabeth. Exclusão digital: um problema tecnológico ou social?. Revista Trabalho e Sociedade. Rio de Janeiro, ano 2, $\mathrm{n}^{\circ}$ especial, dezembro de 2002.

DIAS, Rosilãna Aparecida; LEITE, Lígia Silva. Educação à distância: da legislação ao pedagógico. Petrópolis: Vozes, 2010.

ELIAS, Norbert. O processo civilizador: Uma história dos costumes. Rio de Janeiro: Jorge Zahar Ed., 1994a.

ELY, Débora. Aulas presenciais nas escolas do RS não têm prazo para retorno. GAÚCHAZH, Porto Alegre, v.1, n.1, 29 abr. 2020.

FIORENTINI, Leda Maria Rangearo. A perspectiva dialógica nos textos educativos escritos. In: FIORENTINI, Leda Maria Rangearo; MORAES, Raquel de Almeida (Org.). Linguagens e interatividade na educação à distância. Rio de Janeiro: DP\&A, 2003.

GRUBER, Arthur. Covid-19: o que se sabe sobre a origem da doença. Jornal da USP, 2020.

Revista USP. São Paulo, ano 4, nº 12, setembro de 2020.

HARVEY, David. Condição pós-moderna. São Paulo: Edições Loyola, 1992.

KENISTON, Kenneth; KUMAR, Deepak. It experience in India. Delhi.: Sage Publishers, 2004.

LIMA, Carlos Kennedy Tavares et al. The emotional impact of Coronavirus 2019- nCoV (new Coronavirus disease). London: Psychiatry Research Vol. 287, Issue 1, 2020.

LIVINGTSONE, Sonia; Helsper, Ellen Johanna. Gradations in digital Inclusion: Children, Young People and the Digital Divide. Chicago, New Media \& Society, 4, 671-696, 2007.

MEDINA, Javier. Brecha e inclusion digital en Chile: los desafíos de una nueva alfabetización. Revista Comunicar. Santiago, ano 24, $\mathrm{n}^{\circ}$ 77, 2005.

MINAYO, Maria Cecilia de Souza. Trabalho de campo: contexto de observação, interação e descoberta. In: pesquisa social: teoria, método e criatividade. Rio de janeiro: vozes, 2008.

MOORE, Moore G.; KEARSLEY, Greg. Educação à distância: uma visão integrada. Tradução de Roberto Galman. São Paulo: Cengage Learning, 2011.

OLIVEIRA, Maria Marly. Como fazer pesquisa qualitativa. 3 ed. Petrópolis, RJ: vozes, 2010.

PETERS, Otto. Didática do ensino a distância: experiências e estágio da discussão numa visão internacional. Tradução de Ilson Kayser. São Leopoldo: Unisinos, 2006.

SANTOS, Simone; MENDES, Sílvia; AMARAL, Luís. E-Government e outras políticas públicas para o fomento de participação pública. Revista Core. Minho, ano 4, n 12, 2005.

SATHLER, Luciano. Educação pós-pandemia e a urgência da transformação digital - Anup. O

Povo Online. São Paulo, ano 2, nº 7, 2020.

RIET- ISSN 2676-0355, Dourados, v. 2, n. 2, p. 264 a 285, jan./jun., 2021 


\section{Impacto do ensino remoto na formação dos discentes do curso de engenharia agronômica: UEMG Unidade Ituiutaba - MG}

STEVANIM, Luís Felipe. Desigualdades sociais e digitais dificultam a garantia do direito à educação na pandemia. Rio de Janeiro, RADIS, n.215, AGO 2020.

SILVA, Ketia Kellen Araújo da. Mapeamento de competências: um foco no aluno da educação a distância. 2012. 185 f. Dissertação (Mestrado em Educação) - Universidade Federal do Rio Grande do Sul, Porto Alegre, 2012.

TORRES, Ana Catarina. Educação e Saúde: reflexões sobre o contexto universitário em tempos de COVID-19. Disponível em:

https://www.researchgate.net/publication/341811676_Educacao_e_Saude_reflexoes_sobre_o_cont exto_universitario_em_tempos_de_COVID-19. Acesso em: 25 de setembro de 2020

UNESCO. A Comissão Futuros da Educação da Unesco apela ao planejamento antecipado contra o aumento das desigualdades após a COVID-19. Paris: Unesco, 16 abr. 2020. Disponível em: https://pt.unesco.org/news/comissao-futuros-da-educacao-da-unesco-apela-aoplanejamento-antecipado-o-aumento-das. Acesso em: 05 de agosto de 2020

RIET- ISSN 2676-0355, Dourados, v. 2, n. 2, p. 264 a 285, jan./jun., 2021 